\title{
Polyommatus diana (Lepidoptera, Lycaenidae) Kayseri İli Rhopalocera Faunası için İlk Kayıt ve Erkek Genital Morfolojisi
}

\author{
Erol ATAY ${ }^{*}$, Mehmet ÇELİK ${ }^{2}$ \\ ${ }^{1}$ Mustafa Kemal Üniversitesi Fen Edebiyat Fakültesi Biyoloji Bölümü, Antakya, Hatay, Türkiye \\ ${ }^{2}$ AdaMerOs Kelebek Türkiye, Kelebek Gözlem Topluluğu, Osmaniye, Türkiye. mehmet_celik_80@yahoo.com.tr
}

Geliş Tarihi: 22.07 .2017

*Sorumlu Yazar: eatay@mku.edu.tr

Kabul Tarihi: 20.09.2017

Özet

Kayseri ili Yahyalı ilçesi Düşmüş ve Gökoluk Yaylalarında 1 Mayıs-15 Haziran 2017 tarihleri arasında yapılan kelebek gözlem çalışmalarında Polyommatus diana ilk kez tespit edilmiştir. Arazi ve laboratuvar çalışmaları şeklinde yürütülen bu çalışmada, türün erkek ve dişi bireylerinin ön ve arka kanatlarının renkleri ve desenleri anlatılmış, erkek genital organ preparatı hazırlanarak morfolojisi tarif edilmiş, dişilerin yumurta bıraktığı bitki tespit edilmiştir. Türü tanıtan fotoğraflar bu çalışmada ilk kez verilmiştir. Polyommatus diana Kayseri ili Rhopalocera faunası için ilk kayıttır.

Anahtar Kelimeler: Polyommatus diana, Lycaenidae, Lepidoptera

\section{The First record for Polyommatus diana (Lepidoptera, Lycaenidae) in Kayseri Province of Turkey and Description of Male Genital Morphology of the Species}

\begin{abstract}
Polyommatus diana was detected for the first time in the butterfly observations in Düşmüş and Gökoluk Plateaus of Yahyalı District in Kayseri Province made between 1 May - 15 June 2017. This work carried out in the form of field and laboratory studies, the colors and patterns of the front and hind wings of male and female subjects were described, the male genital slide was prepared and the morphology was described and the host plant in which the females lay eggs was identified. Photographs introducing the species have given for the first time in this study. Polyommatus diana is the first register for Kayseri Rhopalocera fauna.
\end{abstract}

Keywords: Polyommatus diana, Lycaenidae, Lepidoptera 


\section{Giriş}

Mavi kelebekler olarak bilinen Polyommatinae (Lycaenidae) altfamilyası dört kabileyi (Lycaenesthini, Candalidini, Niphandini ve Polyommatini) kapsamaktadır. Bu kabileler arasında Polyommatini kabilesi en çok cinse sahiptir. Bu cinsler içinde de mavi kelebekler olarak bilinen Polyommatus cinsi kozmopolit olup yaklaşık 460 türü içermektedir (Talavera ve ark., 2013).

Avrupa ülkelerinde toplam 90 Lycaenidae türleri bulunurken ülkemizde 130 tür bulunmaktadır (Atay ve Ogur, 2011). Özden ve ark. (2008)'nın yaptığı çalışmada Türkiye'de 349, Lübnan'da 139, Yunanistan'da 232, Mısır'da 58 ve İsrail'de ise Rhopalocera türünün bulunduğu bildirilmiştir. Koçak ve Kemal (2006, 2007, 2009) yıllardır yapmış oldukları faunistik çalışmalarda Türkiye Rhopalocera tür sayısını dokuz familyaya ait toplam 405 tür olarak bildirmişlerdir. Aynı yazarların yapmış oldukları çalışmalar sonucunda Kayseri iline ait Hesperiidae familyasından 17, Papilionidae familyasından 5, Pieridae familyasından 20, Nymphalidae familyasından 12, Libytheidae familyasından 1, Satyridae familyasından 24 ve Lycaenidae familyasından 62 olmak üzere toplam 141 tür listelenmiştir. Kayseri ili Polyommatus cinsi için toplam 33 tür bildirilmiş ve bu cinsin altcinsi olan Neolysandra için ise tek tür olan Çokgözlü Rus Mavisi (Polyommatus (Neolysandra) coelestinus) bulunmaktadır.

Ülkemizde Polyommatus (Neolysandra) diana (Miller, 1913) Ağrı, Erzurum, Gümüşhane, Kars, Bayburt, Bitlis ve Iğdır illerinde yaşamaktadır (Koçak ve Kemal, 2009; Tshikolovets, 2011) (Şekil 1). Von E. Miller Lycaena diana olarak isimlendirdiği türün type lokalitesini Aras Nehri Iğdır (7 erkek 3 dişi birey toplamış) olarak bildirmiş (Miller, 1912). Tshikolovets (2011), tür için çimenlik yamaçlar, subalpin çayırlar ve genellikle 1500-2600 metre arasında volkanik toprakları tercih ettiğini, yılda tek döl verdiğini, yaşadığı bölgeye göre mayıs ortasından temmuz sonuna kadar uçtuğunu bildirmiştir.

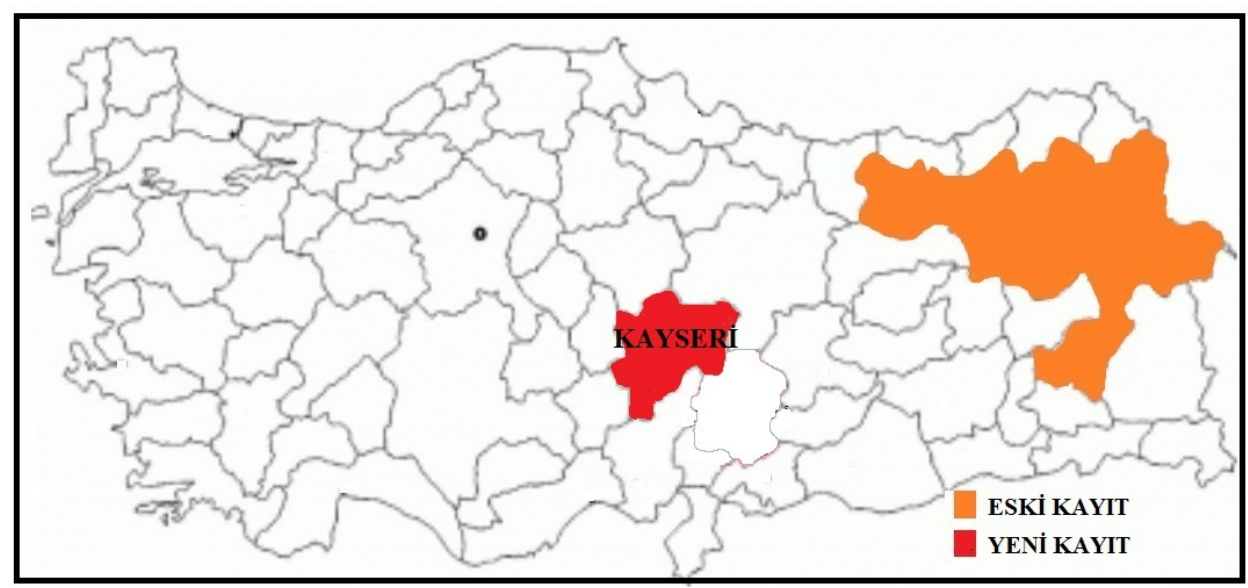

Şekil 1. Polyommatus diana'nın Türkiye'deki dağılımı. 
Karaçetin ve Welch (2011) “Türkiye'deki Kelebeklerin Kırmızı Kitabı” adlı eserlerinde $P$. diana'yı Tehlikede (Endangered, EN) olarak sınıflandırmaktadırlar ve bu nedenle de neslinin doğada tükenme riskinin çok yüksek olduğunu bildirmektedirler.

\section{Materyal ve Metot}

Kayseri ili Yahyalı ilçesi gündüz kelebekleri (Rhopalocera) faunasının tespit edilmesi amacıyla, 1 Mayıs-15 Haziran 2017 tarihleri arasında kelebek fotoğraflama, gözlem ve örnek toplama çalışmaları yapılmıştır. Bu çalışma, araştırma arazi ve laboratuvar çalışmaları şeklinde yürütülmüştür.

\subsection{Arazi Çalışmaları}

1 Mayıs-15 Haziran 2017 tarihleri arasında Kayseri ili Yahyalı ilçesinin Düşmüş Yaylasının ve Gökoluk Yaylasının farklı yükseklik ve bitki örtüsüne sahip lokalitelerinde sürdürülen çalışmamız, kelebek fotoğraflama, gözlem ve örnek toplama işleri Cumartesi ve Pazar günleri yapılmıştır. Kelebeklerin toplamasında $45 \mathrm{~cm}$ çapında ve $75 \mathrm{~cm}$ derinliğinde sık gözenekli atraplar kullanılmıştır. Çalışmanın materyalini Canon EOS 70D dijital fotoğraf makineleri, çeşitli objektifler, alanında bulunan tek y1llık ve çok yıllık kültür ve yabani otlar, çalılar ve ağaçlar üzerinde bulunan ergin gündüz kelebekleri oluşturmaktadır. Gündüz yapılan arazi çalışmaları uygun hava koşullarında (yağışsız ve rüzgarsız) yapılmıştır. Kelebekler bitkiler üzerinde beslenirken, dinlenirken ve yumurta bırakırken fotoğrafları çekilmiştir. Koleksiyon için kelebekler atrap yardımıyla yakalanmıştır. Atrap içerisine alınan kelebekler 10x5x5 cm ebadındaki öldürme kavanozlarına alınmış, oradan da ayrı ayrı petri kutularına yerleştirilmiştir. Arazi çalışması sabahın erken saatinde başlayıp gün batımına kadar sürmüştür.

\subsection{Laboratuvar Çalışmaları}

Laboratuvara getirilen yeni yakalanmış ergin kelebekler, vücut suyunu kaybetmeden özel germe tahtalarında vücut büyüklüklerine göre 1 veya 2 numaralı böcek iğneleriyle iğnelenmiş ve ön ve arka kanat çiftleri usulüne uygun olarak gerilmiştir. Gerilen örneklerin kuruması için oda sicaklığında, nemsiz ve karanlık bir yerde 2 hafta tutularak kurutulmuştur. Kuruması tamamlanan örnekler etiketlenerek saklama ve koleksiyon dolaplarına alınmıştır. Araziden toplanan bazı örnekler özellikle küçük olanlar hızlıca vücut suyunu kaybettiği için kanatları kırılgan hale gelebilmektedir. Bunlar petri kutularına tek tek alınarak özel solüsyonlu (küflenmeyi önleyici \%2'lik fenollü su) filtre kağıtları yerleştirilmiştir. 24 saat sonra bu örneklerin de kanatları gerilmiştir. Kanatları gerilerek 
bütün morfolojik özellikleri ön plana çıkan örneklerin teşhis edilmesi için dişi ve erkek bireylere ait genital organ preparatları hazırlanmıştır. Kelebeklerin iğnelenmesi, kanatlarının gerilmesi ve genital organ preparatları Atay (2006) 'ya göre yapılmıştır. Kelebek teşhisleri Mustafa Kemal Üniversitesi Fen Edebiyat Fakültesi Biyoloji Bölümü Zooloji Anabilim Dalı laboratuvarında tarafımızdan yapılmıştır.

\section{Bulgular ve Tartışma}

Polyommatus (Neolysandra) diana (Miller, 1913) Çokgözlü Diana Mavisi (Şekil 2.)

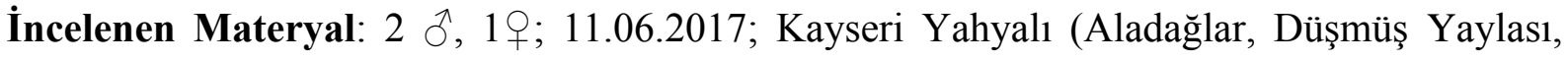
3757'33” N; 35²0’08” E, 1883 m. ve Gökoluk Yaylası 3755’57” N; 35¹8’10” E, 2253 m.)

Konukçu Bitki: Lathyrus brachypterus var. brachypterus Celak, 1888 (Fabaceae)

Arazide Uçuş Dönemi: mayıs sonu temmuz başı.

ઈ Kanat açıklığı $31 \mathrm{~mm}$., vücut uzunluğu $12 \mathrm{~mm}$.

† Kanat açıklığı $33 \mathrm{~mm}$., vücut uzunluğu $11 \mathrm{~mm}$.

Erkeklerde ön ve arka kanat üst zemini morumsu parlak mavidir; ön kanatların orta dış yarısı ve üst kenar boyu siyahımsı fümeye çalan renktedir. Arka kanat benzer renklenmeyi gösterir, ancak dış kenar çok az siyahımsı fümedir. Ön ve arka kanatların damarlarının üzeri hafif füme olup çok belirgindir. Ön kanat üzerinde siyah diksel benek oldukça belirgindir. Ön ve arka kanat altı siyahımsı gridir, ön kanat altında siyah beneklerden oluşan orta dış benek bandı arka kanattakine oranla daha büyüktür ve her benek ince beyaz halkalıdır. Kanat ortasında bulunan diksel benek siyahtır. Ön kanat kaidesinde çok küçük alanda yeşilimsi parlak mavi renklenme vardır. Arka kanat altı ön kanat altına benzerdir, ancak orta dış benek bandını oluşturan siyah benekler daha küçüktür ve anal açı yakınında birkaç benek eksik olabilir. Bazı bireylerde kanat altı dış kenara kadar bazılarında ise diksel benek civarına kadar yeşilimsi parlak mavi pulludur. Bu türü kolay tanımak için; arka kanat altında bulunan, çoğunlukla beyaz bazı bireylerde ise küçük siyah benekli diksel beneğinden orta dış benek bandına kadar uzanan çok ince beyaz renkte çizgiyi görmek yeterli olacaktır.

Dişilerde ön ve arka kanat üstü kahverengidir ve ön kanatta siyah diksel benek çok belirgindir. Arka kanatta birkaç tane silik mavi renkte kenar alt beneği bulunur. Bu bazı bireylerde görülmez. Ön ve arka kanat altı grimsi kahverengidir ve desenlenme erkeğe benzerdir, ancak orta dış benek bandını oluşturan benekler daha büyüktür. Arka kanat altında kanat bazalı erkeğe oranla daha az yoğun mavimsidir. Arka kanat disksel beneğin ince uzun beyaz çizgisi çok belirgindir. 

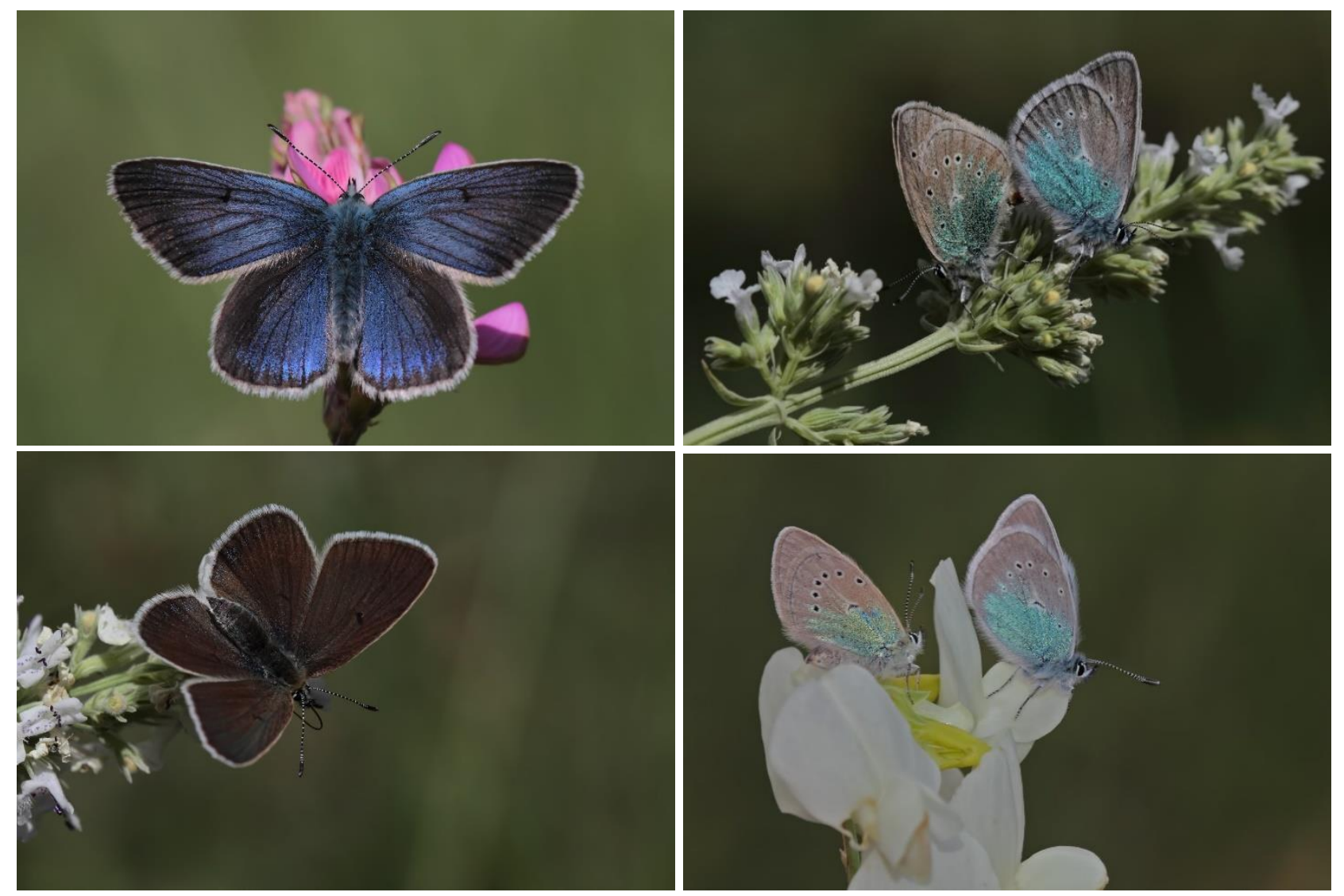

Şekil 2. P. diana'nın erkek ve dişi kanat üstü ve kanat altı.

\section{Erkek Genital Organı}

Aedeagus kısa, kalın ve silindirik çomak şeklindedir, orta kısın daha ince ön ve arka uçlar geniştir; uzunluğu genişliğinin 3.33 katıdır (Şekil 3.) Valva uzundur, uzunluğu genişliğinin 3.24 katıdır; üst kenar orta bölgede kuvvetlice köşe oluşturmuştur ve dış uca doğru kalınca içe kıvrılmıştır (Şekil 4.). Bu yapı uçta kuvvetlice aşağıya doğru kısa bükülerek kuş gagasına benzer bir şekil almıştır. Bu yapının hemen altında dışa doğru çıkıntı yapan zarımsı vental katlanma oldukça belirgindir. Valva üzerinde az çok uzun ve sert kıllar bulunmaktadır. Kıllar üst ve alt kenarlarda daha uzundur. Valvanın orta kısmında zarımsı katlanma görülmektedir. Uncus oldukça geniş bir çift kürek şeklindedir ve üzerinde seyrek kıllar bulunmaktadır (Şekil 5.). Uncusun hemen altında bir çift kuvvetlice kıvrılmış ve uca doğru sivrilmiş çengel şeklinde brachium bulunmaktadır. Tegumen kısa ve geniştir. Vinculum ve saccus kitin yapıda olup incedir (Şekil 6.). 


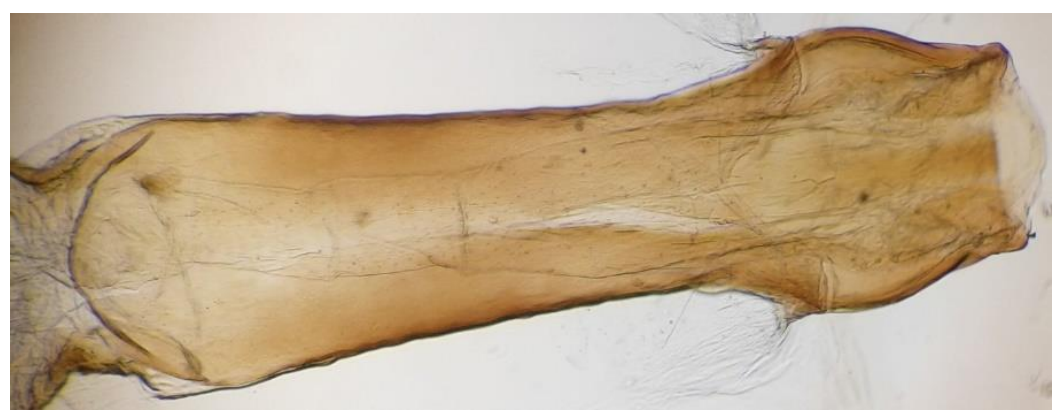

Şekil 3. Aedeagus'un yapısı.

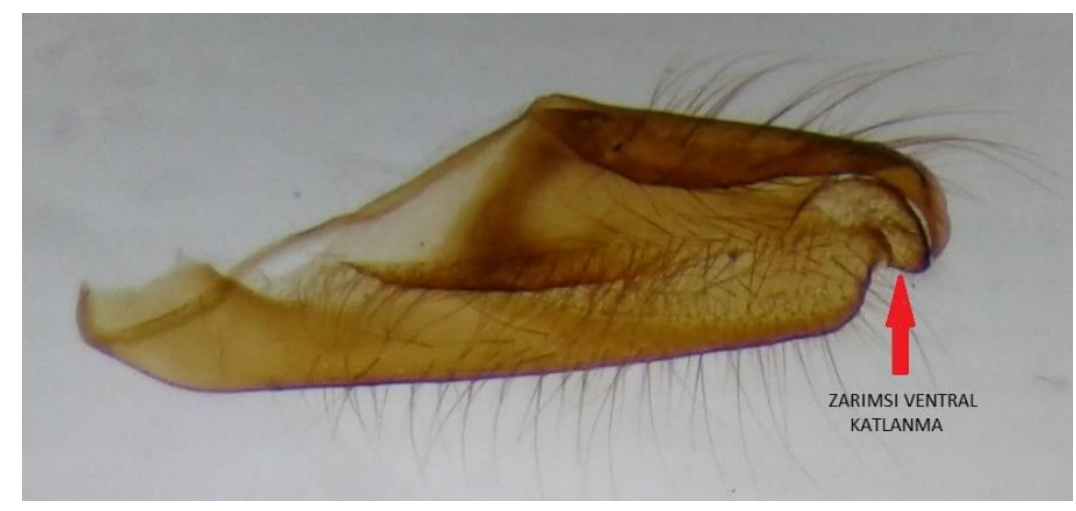

Şekil 4. Valva'nın yapısı.

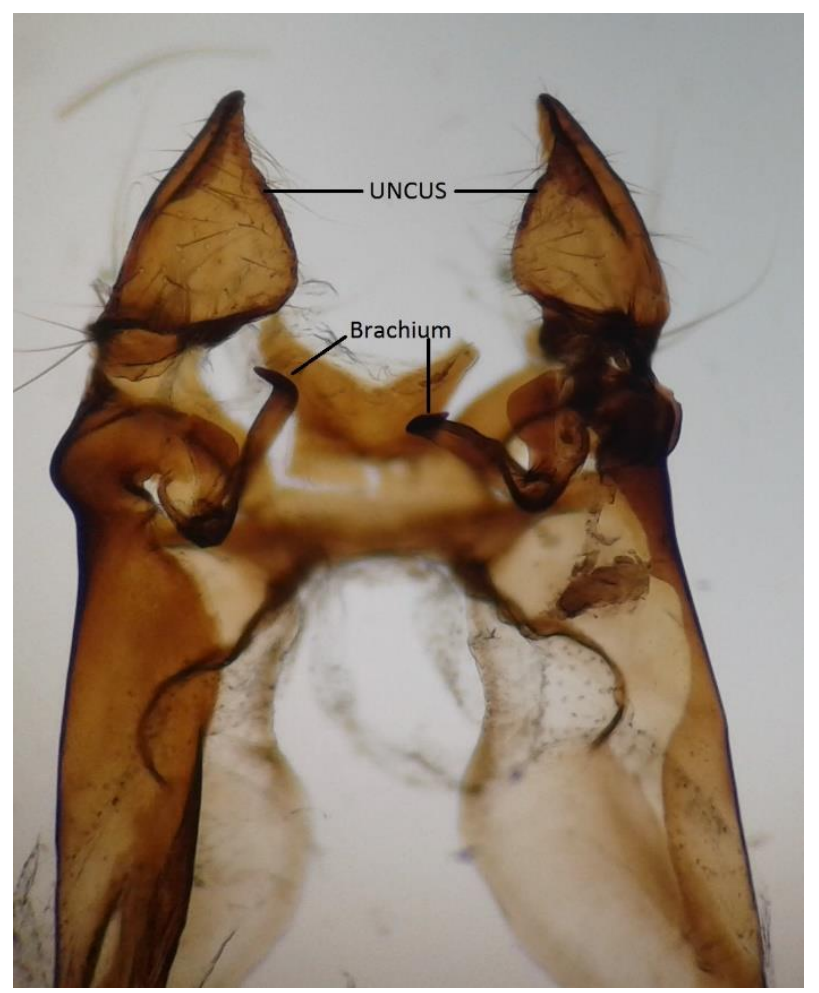

Şekil 5. Uncus'un yapıs1. 


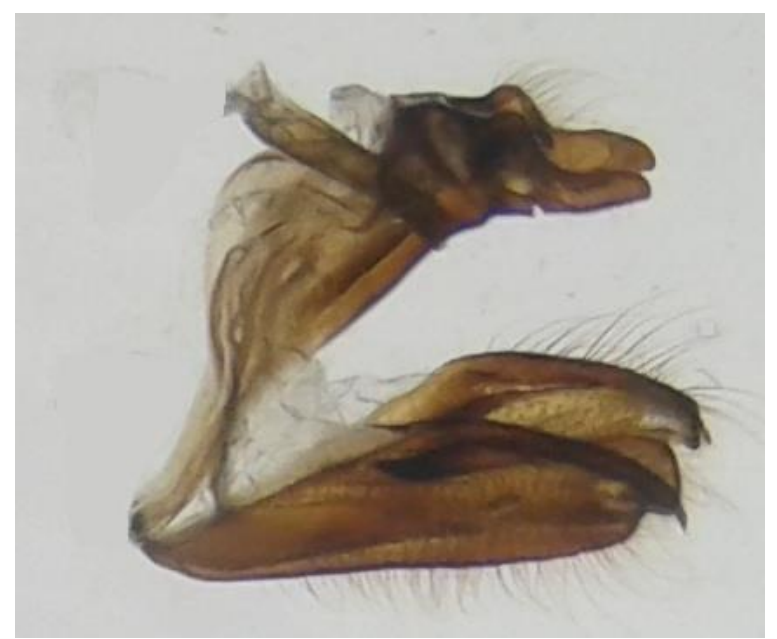

Şekil 6. Erkek genital organının genel yapısı.

Arazi gözlem çalışmaları sırasında erkekler ve dişiler takip edilerek dişilerin yumurta bıraktığı bitki tespit edilmiştir. Dişiler Fabaceae familyasından Lathyrus brachypterus yapraklarının üstüne veya altına birer tane yumurta bırakmaktadır (Şekil 7.). Ülkemizde konuk bitkinin endemik iki alttürü bulunmaktadır. Lathyrus brachypterus var. brachypterus Celak, 1888 Hatay, Ankara, Kayseri, Adana, Kahramanmaraş ve Niğde illerinde yaygındır. Lathyrus brachypterus var. haussknechtii (Sirj., 1934)Doğu Anadolu'da yaygın olup Nigde, Tunceli, Erzurum ve Van illerinde bulunmaktadır (Devis, 1970).
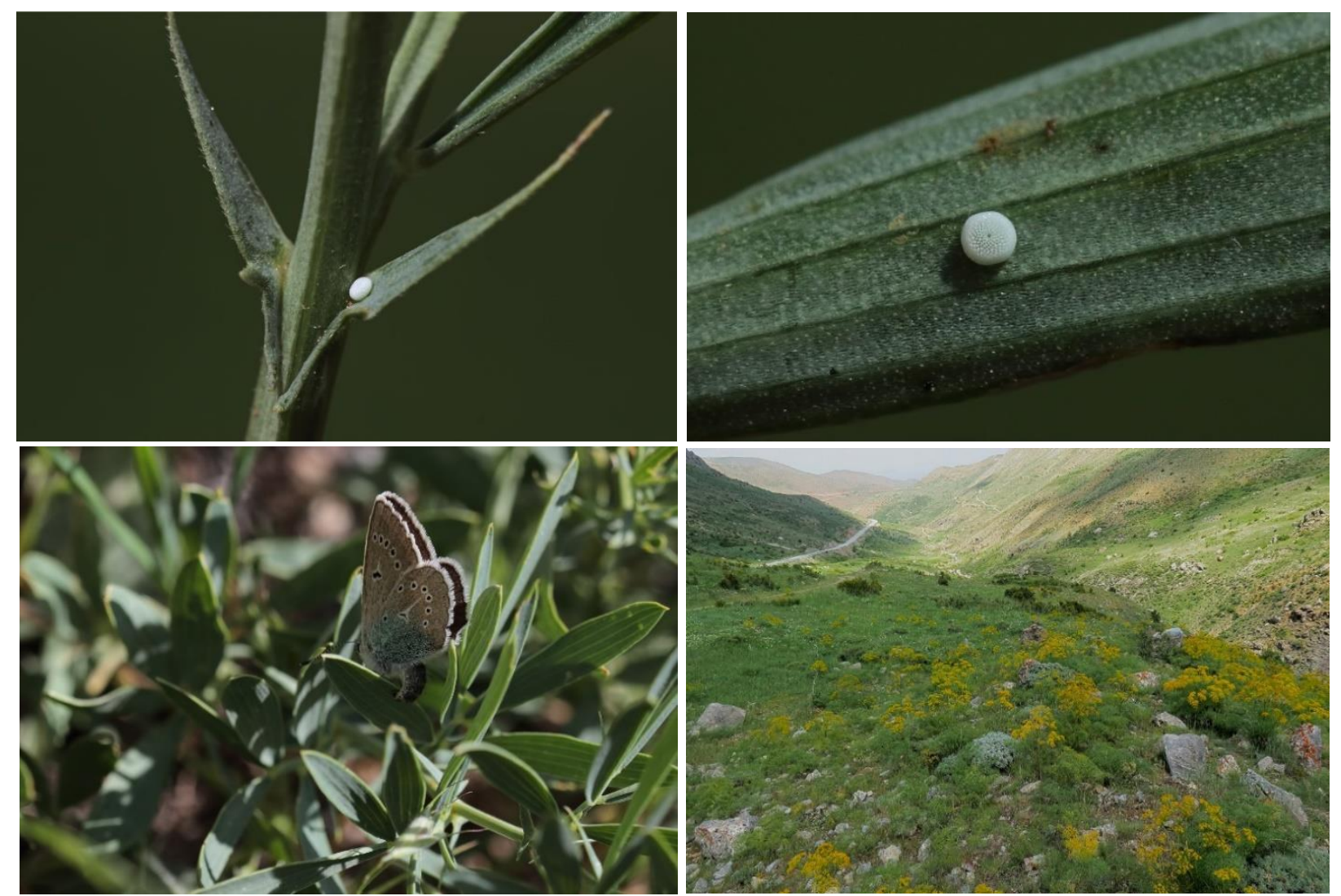

Şekil 7. P. diana'nın yumurtası, konukçu bitkisi (Lathyrus brachypterus var. brachypterus ) ve yaşam alanı. 


\section{Sonuç}

Çokgözlü Diana Mavisi, Kayseri ilinde ilk kez 04.06.2017 tarihinde gözlemlenmiştir. Polyommatus diana Kayseri ili Rhopalocera faunası için yeni kayıttır. Türün dişilerinin konukçu bitki yapraklarına yumurta bırakmaları ilk kez bu çalışma ile fotoğraflanmıştır. Ayrıca, erkek bireylere ait genital organ morfolojisi de bu çalışmada tarif edilerek fotoğrafları verilmiştir.

\section{Teşekkür}

Arazi çalışmalarında bizlere yardımcı olan ve türü ilk fotoğraflayan Abdülkadir Şahin'e teşekkür ederiz.

\section{Kaynaklar}

Atay, E. (2006). The Identity of Parapoynx affinialis (Guenée, 1854) (Lepidoptera, Crambidae, Nymphulinae)' in Turkey. Journal of Entomology, 3 (1): 76-81.

Atay, E,. and Oğur E., (2011). Occurrence of species of Pyralidae and Crambidae in Cyprus. Zoology in the Middle East, 53, 79-86.

Karaçetin, E. ve Welch, H. J. (2011). Türkiye'deki Kelebeklerin Kırmızı Kitabı. Doğa Koruma Merkezi, 125 pp., Ankara, Türkiye.

Koçak, A. Ö. and Kemal, M. (2006). Checklist of the Lepidoptera of Turkey. Centre for Entomological Studies Ankara, 1: 1-196.

Koçak, A. Ö. and Kemal, M. (2007). Revised and annotated checklist of the Lepidoptera of Turkey. Centre for Entomological Studies Ankara, 8: 1-150.

Koçak, A. Ö. and Kemal, M. (2009). Revised checklist of the Lepidoptera of Turkey. Centre for Entomological Studies Ankara, 17: 1-150.

Miller, Von E. (1912). Neue Rhopalocera aus Transkaukesien. Deutsche Entomologische Zeitschrift Iris. 16 (4), 220-222.

Ozden O., Ciesla, W. M., Fuller, W. J., Hodgson, D. J. (2008). Butterfly Diversity in Mediterranean Islands and in Pentadaktylos Pinus brutia Forest of Cyprus. Biodivers Conserv, 17: 2821-2832.

Talavera, G., Lukhtanov, V. A., Pierce, N. E. and Vila, R. (2013). Establishing criteria for higher-level classification using molecular data: the systematics of Polyommatus blue butterflies (Lepidoptera, Lycaenidae). Cladistics. 29, 166-192.

Tshikolovets, V. V. (2011). Butterflies of Europe and Mediterranean area. Czech Republic: Tshikolovets Publications. 